\title{
NUMERICAL PREDICTION OF STRESSES AT HIGH TEMPERATURE OF 3RD GENERATION ADVANCED HIGH STRENGTH STEELS DURING RESISTANCE SPOT WELDING - LIQUID METAL EMBRITTLEMENT RISK ASSESSMENT
}

\section{METHODOLOGY TO CREATE AND VALIDATE A RELIABLE AND ROBUST NUMERICAL MATERIAL CARD}

\author{
H.LEJAULT ${ }^{1,2}$, S.GAIED ${ }^{1}$, A.GAYET ${ }^{1}$, M.RISBET ${ }^{2}$ AND J.FAVERGEON $^{2}$ \\ ${ }^{1}$ ArcelorMittal Global R\&D Montataire (France) \\ Route de Saint-Leu, 60160 Montataire \\ helena.lejault@arcelormittal.com \\ ${ }^{2}$ Université de Technologie de Compiègne, Laboratoire Roberval, Compiègne (France) \\ Rue du Dr Schweitzer, 60200 Compiègne \\ helena.lejault@utc.fr / marion.risbet@utc.fr / jerome.favergeon@utc.fr / https://roberval.utc.fr/
}

Key words: 3rd generation of Advanced High Strength Steels (AHSS), Resistance Spot Welding (RSW), Liquid Metal Embrittlement (LME), Numerical material card, Multi-physical modelling, Numerical simulation

\begin{abstract}
The prediction of stress level during Resistance Spot Welding at high temperature is very useful to reduce and/or avoid Liquid Metal Embrittlement phenomenon. However, the experimental estimation of stress level into metal sheets during a Resistance Spot Welding process is impractical. Therefore, a numerical methodology to predict mechanical stresses, using more accessible experiments, is proposed in this work.
\end{abstract}

\section{INTRODUCTION}

Resistance Spot Welding is the most used process in the assembly of automotive structures. The body in white, which is the safety structure of a vehicle, is assembled by means up to 6000 spot welds (Figure 1). For some parts of the automotive structure, $3^{\text {rd }}$ generation Advanced High Strength Steels $[1,2]$ are used in order to improve the safety and reduce the weight and cost of vehicles.

Resistance Spot Welding process (Figure 2, Figure 3) fastens together metal sheets with two electrodes applying current. The resistance spot welding process is composed of 3 steps:

- $\quad$ First, the electrodes squeeze the sheets with a pressure around 200 to 600 daN;

- $\quad$ Then, welding current, between 5 to $20 \mathrm{kA}$, is applied;

- $\quad$ Finally, current application is stopped, and cooling is done under pressure to avoid expulsion of liquid metal from the nugget and to assure the good welding of sheets.

All these steps are needed to create a robust spot weld. However, during resistance spot 
welding of 3rd generation Advanced High Strength Steel sheets with zinc coating, the Liquid Metal Embrittlement phenomenon may occur [4, 5]. This phenomenon corresponds to the penetration of liquid zinc of the coating in the grain boundaries of the steel at high temperature $[6,7]$, in a zone under high internal stress. It creates cracks [8] between the Heat Affected Zone (HAZ) and the base metal (Figure 4).

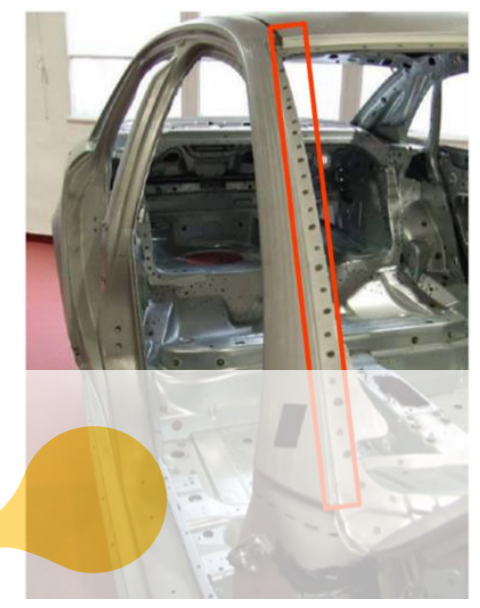

Figure 1: Spot welds locations in the body in white of a automotive structure [3]
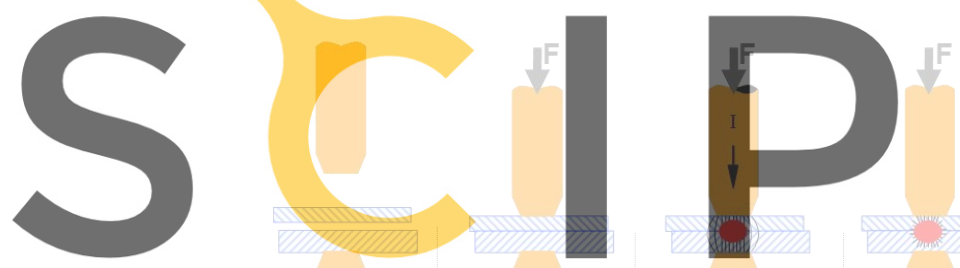

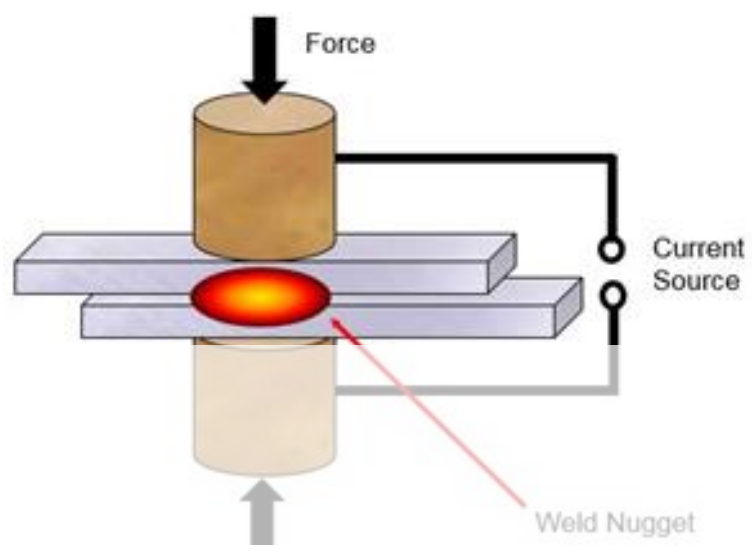

Figure 2: Creation of the liquid weld nugget during Resistance Spot Welding process
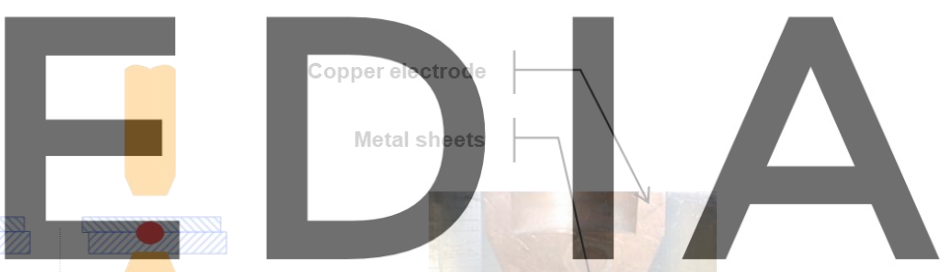

Register for free at https//www.scipedia.com to download the version without the watermark

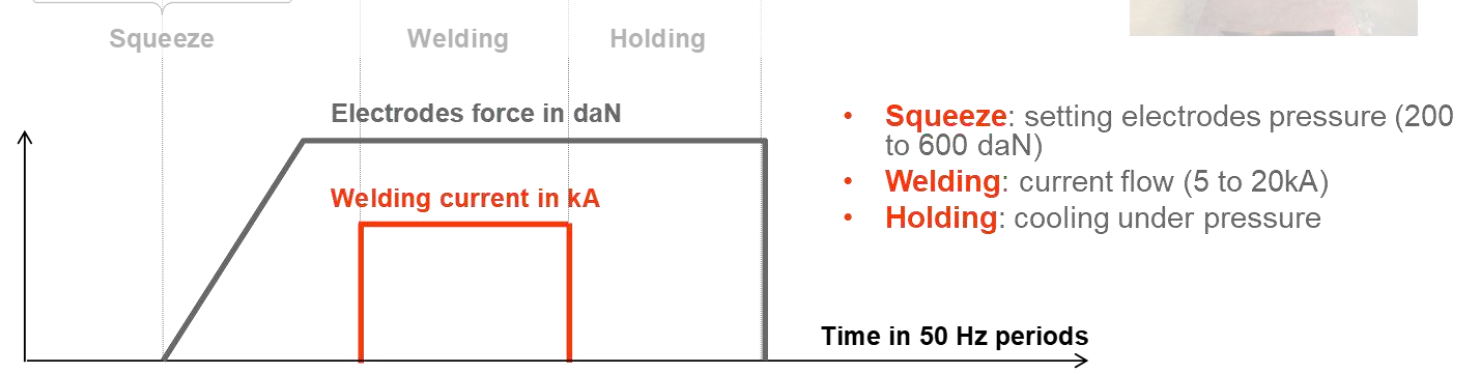

Figure 3: Schematic representation of the Resistance Spot Welding process [3] 


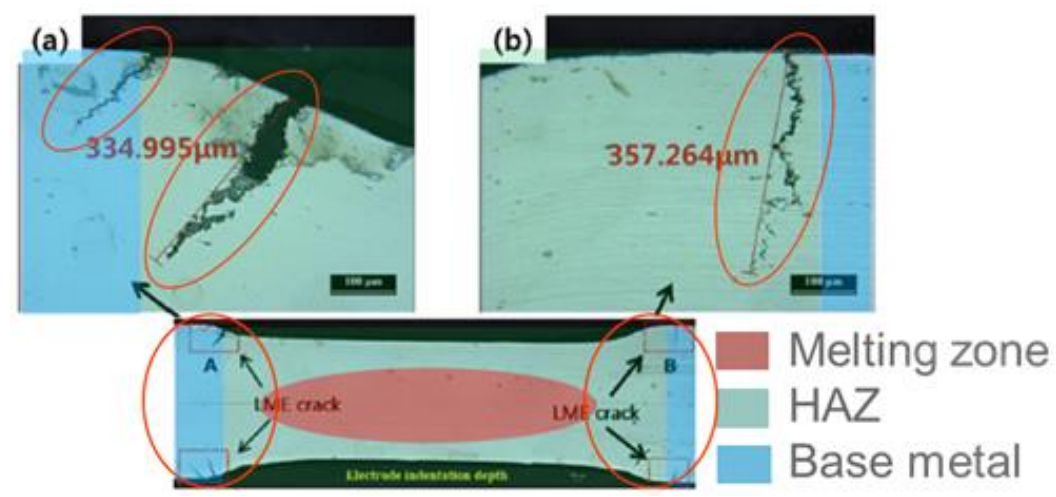

Figure 4: Observation of Liquid Metal Embrittlement cracks in a Resistance Spot Welded Advanced High Strength Steel [9]

Several factors act simultaneously to generate Liquid Metal Embrittlement phenomenon during Resistance Spot Welding: the presence of liquid zinc at the surface of sheet, the wetting of steel grain boundaries, the duration of welding or the internal stress level higher than a critical stress value, for example. We decided to focus our work on the internal stresses opening and propagating cracks because this parameter plays a significant role on Liquid Metal Embrittlement phenomenon [9 - 16].

The objective of the global work is to predict numerically the location and the intensity of internal stresses generating Liquid Metal Embrittement, during the Resistance Spo of $3^{\text {rd }}$ generation of Adv high temperature) and would aim to find the the Liquid Metal Embri For this study, the studied steel belongs to
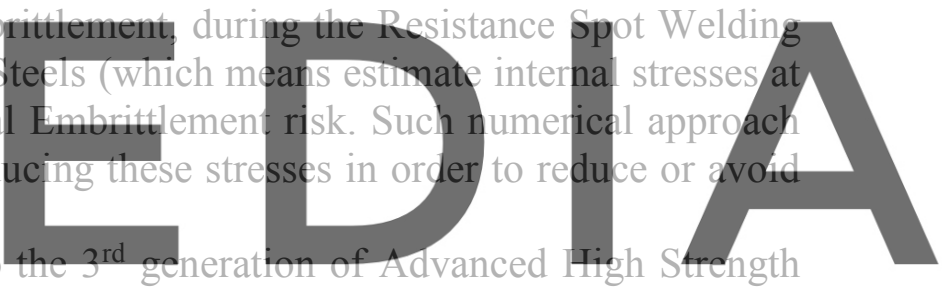
Steels (Table 1).

Register for free at https//www.scipedia.com to download the version without the watermark Table 1: Properties of the 3rd generation of Advanced High Strength Steel studied

\begin{tabular}{cccc} 
Direction & YS $(\mathrm{MPa})$ & TS $(\mathrm{MPa})$ & TEI\% \\
\hline ISO-RD & $>850$ & $>1180$ & $\geq 13$ \\
\hline
\end{tabular}

For the numerical simulation, we use two software of ESI Group: Visual-Environment ${ }^{\circledR}$ software for the multi-physical modelling and Sysweld ${ }^{\circledR}$ software for the multi-physical numerical calculation. The first step of this work is to create the numerical steel used in software. All properties of the steel are implemented into a database named a material card. Then, properties of the material card are assessed and validated comparing experimental and numerical results of thermo-mechanical tests like dilatometry, high heating rate tensile test or Resistance Spot Welding. Finally, the validated material card is used in the Resistance Spot Welding model in order to estimate the position and the intensity of the internal stresses in the steel sheets; such simulation will allow us to optimize the welding parameters for stress reduction.

Therefore, the main challenge is to create and validate a reliable material card of the Advanced High Strength Steel to simulate thermal, mechanical, metallurgical and electrical coupling in order to implement this card in the Resistance Spot Welding numerical model. 
Eventually, having all properties of steel for each phase on a large temperature range, from the room temperature to the liquid state, is experimentally and numerically complicated. For instance, obtaining properties of austenite at temperatures lower than Acl is quite impossible from an experimental point of view. Thus, these properties are calculated with software thanks to the chemical composition of the steel but are not directly obtained experimentally.

Phenomena related to microstructure and the Liquid Metal Embrittlement phenomenon itself as the penetration of liquid zinc at grain boundaries and the zinc coating will not be represented in the numerical model of the Resistance Spot Welding. We will only focus our work on welding parameters and the stresses generated during the process.

\section{CREATION OF THE NUMERICAL MATERIAL CARD}

The creation of the material card is the first and the most important step of this work. Indeed, if the numerical properties of the steel are different from the real steel properties, numerical calculation will not be reliable and the internal stresses calculated will be wrong. Therefore, the creation of a reliable and robust material card is the core of this work in order to predict precisely the location and the intensity of internal stresses in steel sheets during Resistance Spot Welding.

2.1 Properties

The numerical material card is a database containing mechanical, thermal, electrical and metallurgical properties of the studied steel
temperature and temperature rate, but also
metallurgical dependence of the properties
polyphasic and contains residual austerite.
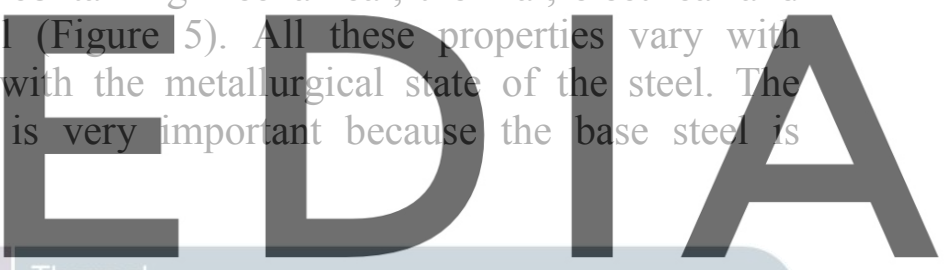

Register for free at https//www.scipedia.com to download the version without the watermark

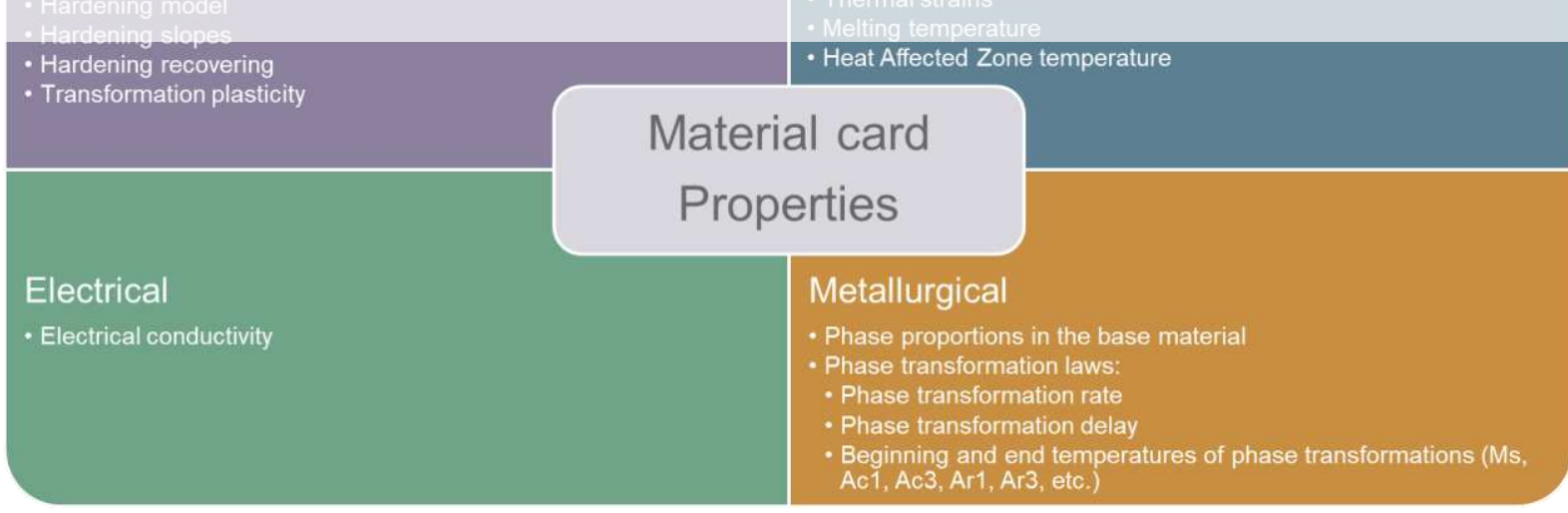

Figure 5: Type of properties implemented into the numerical material card

One issue of the present work is to obtain properties for each phase from the room temperature to above melting temperature, in order to have a good representation of the numerical steel during heating and cooling. 


\subsection{Focus on metallurgical properties}

Several models are needed to integrate and validate physical properties depending on temperature and heating/cooling rate. Here, we focus particularly on metallurgical properties which are assessed from experimental dilatometry test with a representative model. We use experimental data obtained in a dilatometry test performed in ArcelorMittal.

\subsubsection{Presentation of dilatometry test}

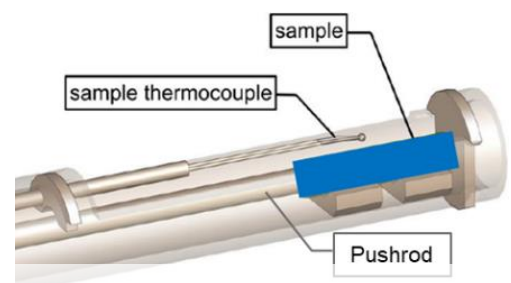

Figure 6: Location of the pushrod and the thermocouple measuring dilatation and temperature of a sample during dilatometry test

Dilatometry test, carried out with a dilatometer Bähr DIL805A, measures the thermal dilatation of the specimen depending on the temperature. A pushrod and a displacement device measure the displacement of the free surface and a thermocouple (R-type) measures the

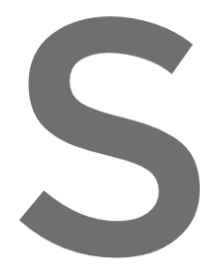
temperature of the sam

${ }^{\circ} \mathrm{C} / \mathrm{s}$ from the room temperatur gaz.

Register for free at https//www.scipedia.com to download the version without the watermark

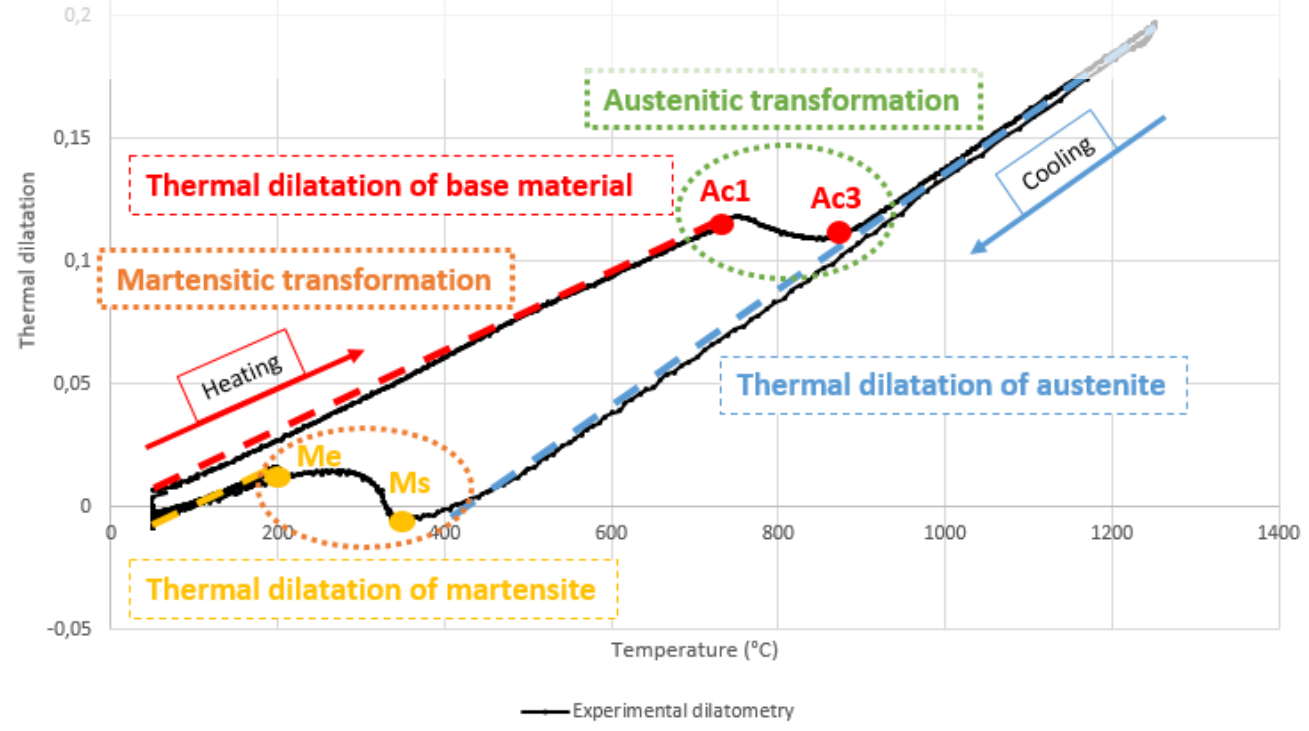

Figure 7: Parameters and properties highlighted with an experimental dilatometry curve 
The measured thermal dilatation is plotted versus temperature (Figure 7). This curve allows to follow the thermal dilatation/contraction of the simple that follows different metallurgical transformations and to determine characteristic temperatures, such as:

- $\quad$ The thermal dilatation of the base material during heating (dashed red line);

- $\quad$ The thermal dilatation and contraction of austenite during heating and cooling (dashed blue line);

- $\quad$ The thermal contraction of martensite during cooling (dashed yellow line);

- $\quad$ The characteristic steel temperatures (Ac1, Ac3, Ms and Me).

Between these three distinct thermal dilatation or contraction regimes, two phenomena are highlighted:

- The austenitic transformation characterized by the contraction of the steel specimen (dashed green ring);

- $\quad$ The martensitic transformation characterized by the dilatation of the specimen (dashed orange ring).

\subsubsection{Metallurgical transformation laws}

Characteristic temperatures and metallurgical transformation curves obtained with dilatometry test are used to calibrate the parameters of metallurgical transformation laws implemented in the numerical software.

The first law is the Kolmogorov-Johnson-Mehl-Avrami equation (1) [17] and concerns all diffusive metallurgical transformations during heating an of the phase created durit the temperature and the
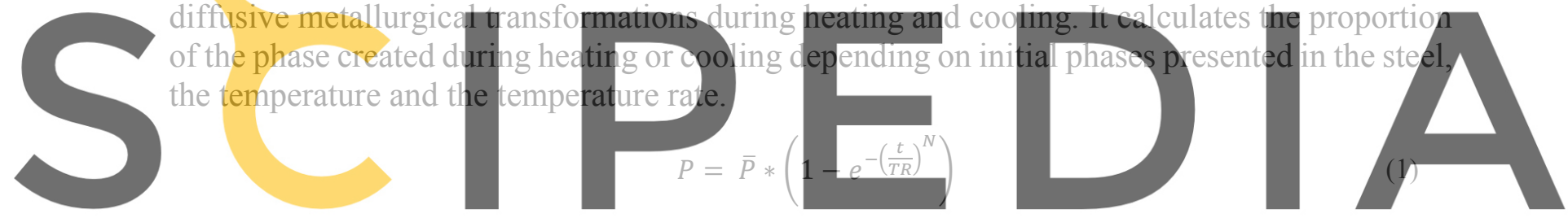

P: Proportion of created phase, t: Time (s), $\overline{\mathrm{P}}$ : Proportion of initial phase, TR: Transformation

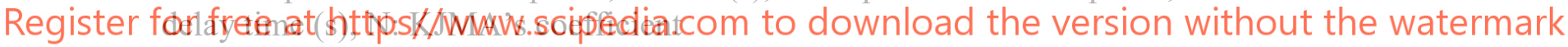

The second law is the Koistinen-Marburger equation (2) [18] and concerns the martensitic transformation during cooling. It calculates the proportion of martensite created during quenching depending on proportion of austenite before cooling, the temperature and Martensite start temperature.

$$
P_{\alpha^{\prime}}=P_{\gamma} *\left(1-e^{(-\alpha[M s-T])}\right)
$$

$\mathrm{P}_{\alpha}$ : Proportion of martensite created, Ms: Martensite start temperature $\left({ }^{\circ} \mathrm{C}\right), \mathrm{P}_{\gamma}$ : Proportion of austenite, T: Temperature during cooling $\left({ }^{\circ} \mathrm{C}\right), \alpha$ : KM's coefficient $\left({ }^{\circ} \mathrm{C}^{-1}\right)$

\section{VALIDATION OF MATERIAL CARD AND NUMERICAL CALCULATIONS}

After the creation of the numerical material card, we have to validate its reliability for the numerical simulation. We performed different experimental tests to measure experimentally some values and we developed numerical model in order to compare experimental and numerical results. 


\subsection{Validation of thermal/metallurgical coupling}

To validate the thermal/metallurgical coupling, the dilatometry test is simulated with the Sysweld ${ }^{\circledR}$ software (ESI Group), using an adaptive time step. The experimental temperature cycle is reproduced numerically on a parallelepiped sample with dimensions corresponding to the experimental one $\left(10 \times 4 \times 1.6 \mathrm{~mm}^{3}\right)$, and the displacement is calculated at each time step. As an example, left part of Figure 8 presents the calculation of the temperature map in the specimen and the right part the displacement of the free surface of the specimen during the temperature cycle.

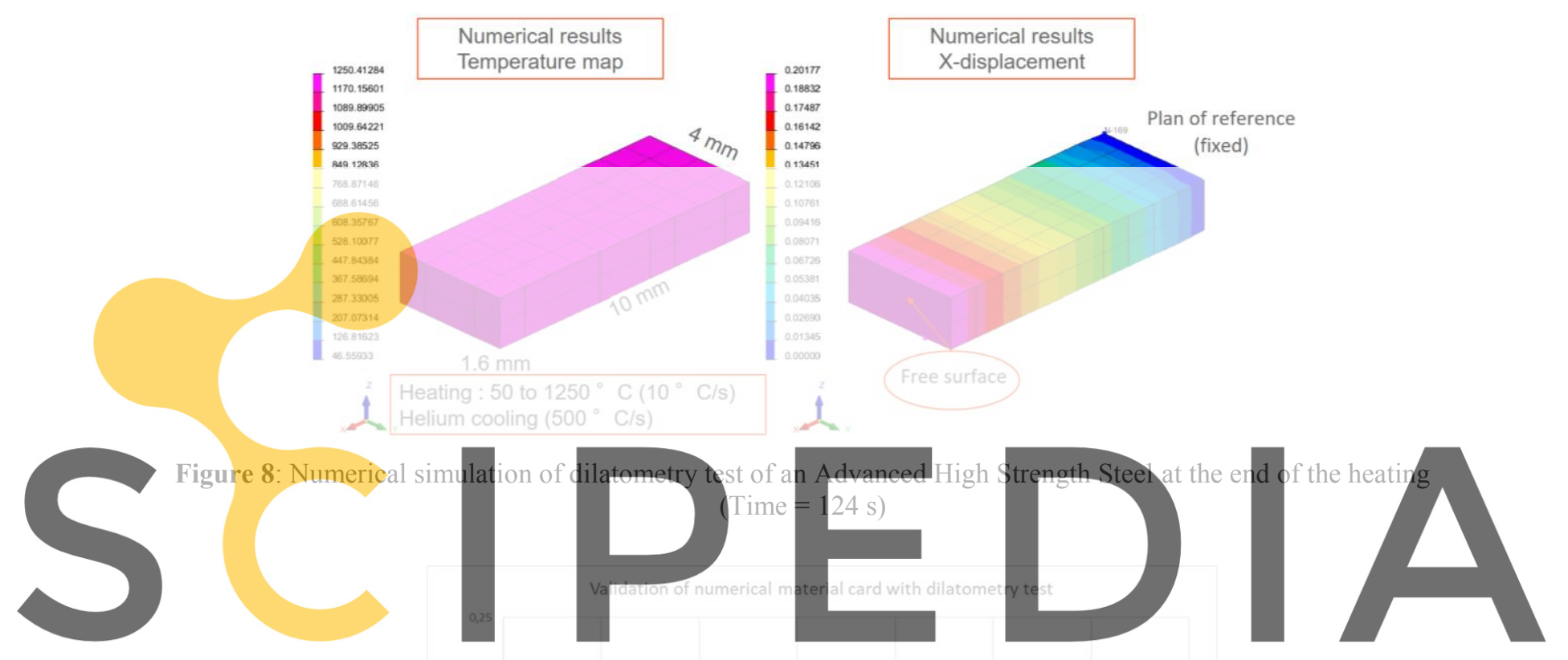

Register for free at https//www.scipedia.com to download the version without the watermark

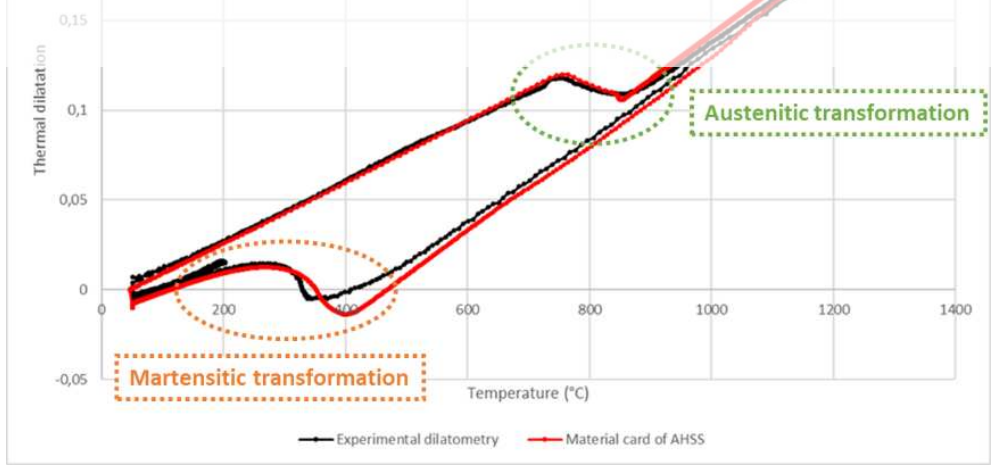

Figure 9: Comparison of experimental (black curve) and numerical (red curve) results of a dilatometry test (Heating at $10{ }^{\circ} \mathrm{C} / \mathrm{s}$ from the room temperature to $1250{ }^{\circ} \mathrm{C}$ and helium cooling at $500{ }^{\circ} \mathrm{C} / \mathrm{s}$ )

The simulation takes the metallurgical state of the steel at each temperature (percentage of phases) into account, but also the changes in volume that occur during phase changes. The results of the simulation allow to plot the dilatometry curve (thermal dilatation of the free 
surface vs temperature) which can be compared to the experimental one. Figure 9 shows this comparison after optimization of the metallurgical properties in the numerical material card. The relative agreement between numerical and experimental curve allows to validate the data properties used for the thermal dilatation and metallurgical transformation calculations.

\subsection{Validation of strong thermal/mechanical/metallurgical/electrical coupling}

The second step of this work concerns the optimization of electrical and mechanical properties of the numerical material card. For this purpose, a hot temperature tensile test at high heating rate is used. This test is performed on a Gleeble ${ }^{\circledR}$ platform available at ArcelorMittal. The sample is a tensile test specimen with a reduced section in the gage zone. First, the specimen is heated by Joule effect at $1000{ }^{\circ} \mathrm{C} / \mathrm{s}$ from the room temperature to $950{ }^{\circ} \mathrm{C}$. Then, at $950{ }^{\circ} \mathrm{C}$, the specimen is elongated by $2 \mathrm{~mm}$ at $2 \mathrm{~mm} / \mathrm{s}$ and finally pulsed cold helium cooled. The thermal control during the test, is performed thanks to a thermocouple placed in the centre of the gage zone and a force sensor in jaws measures the longitudinal force (Figure 10).

This test is reproduced numerically with the Sysweld $\left(\mathbb{R}_{\text {s }}\right.$ software. The electric properties of the steel are validated by comparison of the calculated temperature (Figure 11 - top map) with the experiment value at the centre of the specimen.

Experimental and numerical results of the mechanical test (longitudinal stresses) are in good agreement after optimization of any mechanical parameters in the material card. We numerically and experimentally observe, in the gage zone, compressive stresses during the

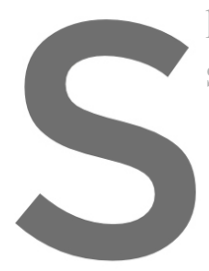
heating (Figure 11 - bottom map), tensile stres
stresses during the martensitic transformation
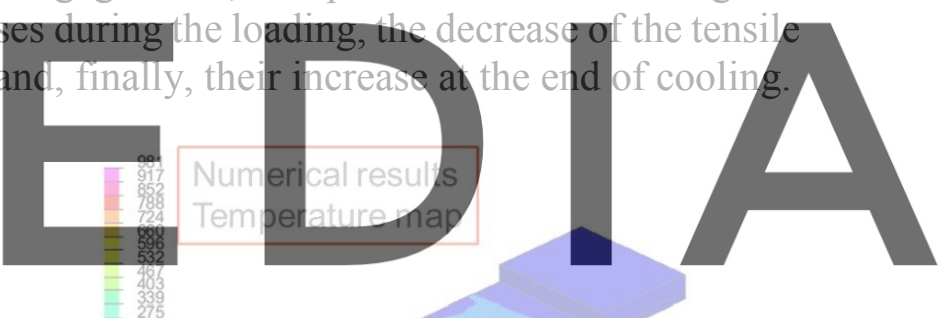

Register for free at https//www.scipedia.com to downlibad the version without the watermark

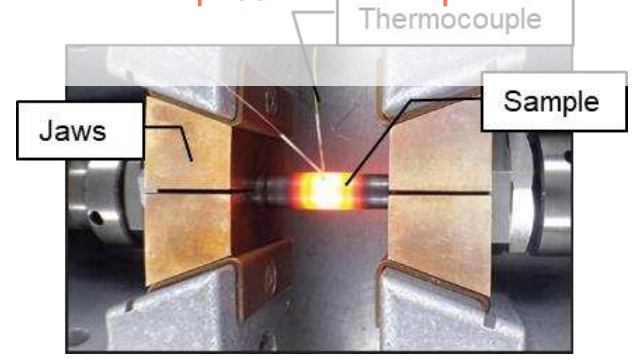

Figure 10: Location of the sensor force and the thermocouple measuring force reaction applied and temperature of a sample during high temperature and loading rates tensile test
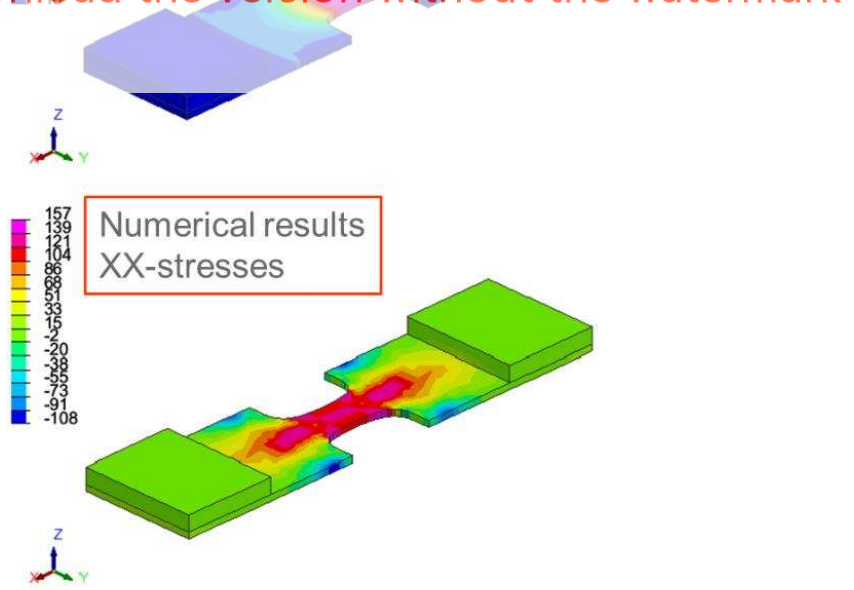

Figure 11: Numerical simulation of a hot tensile test at high temperature rate at $950^{\circ} \mathrm{C}$ at the end of tensile test just before final cooling (time $=5.2 \mathrm{~s}$ ) 


\section{APPLICATION TO RESISTANCE SPOT WELDING SIMULATION}

The optimized material card is used for the simulation of the resistance spot welding of two steel sheets. The model allows the simulation of the liquid state of the steel during Resistance Spot Welding because temperature is higher than the melting temperature during the process. The liquid/austenic phase change has not been evaluated with the hot temperature tensile test and dilatometry test simulations. Indeed, the Resistance Spot Welding simulation highlights that some properties, like thermal conductivity of the liquid phase, have a great impact on the temperature into the liquid nugget and on the nugget size. Nevertheless, no experimental data are available for the Advanced High Strength Steel thermal conductivity in the liquid state.

Figure 12 gives the evolution of the local maximum temperature of the steel, versus time, during the simulation of the Resistance Spot Welding, and the values of the steel thermal conductivity versus temperature, implemented in the material card. For the first curve of the thermal conductivity (blue line), the material card considers a constant value for steel thermal conductivity in the $20^{\circ} \mathrm{C}-1400^{\circ} \mathrm{C}$ temperature range (this value corresponds to the austenite value). Thus, when the temperature is above the melting temperature $\left(1400^{\circ} \mathrm{C}\right)$, the simulation still considers the austenite thermal conductivity. As a consequence, the maximum temperature reaches in the weld nuggets is higher than expected (experimentally, this maximum temperature is about $2000^{\circ} \mathrm{C}$ ).

Thanks to literature [19], the thermal conductivity of the steel has been extrapolated for temperature higher than the melting temperature (Red curve in Figure 12). The extrapolated

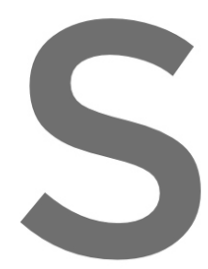
thermal conductivity otherwise this property

Using such extrapolati in the liquid nugget (red curve). Consequently, liquid state of the steel creates a more realistic
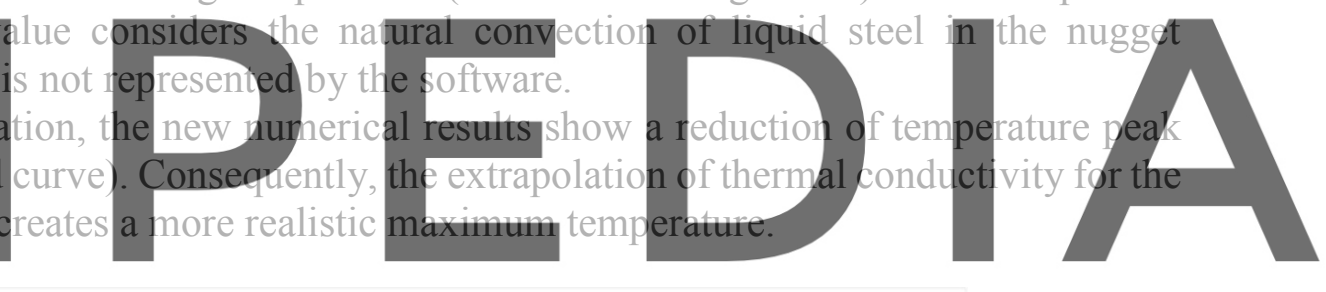

Register for free at https//www.scipedia.com to download the version without the watermark

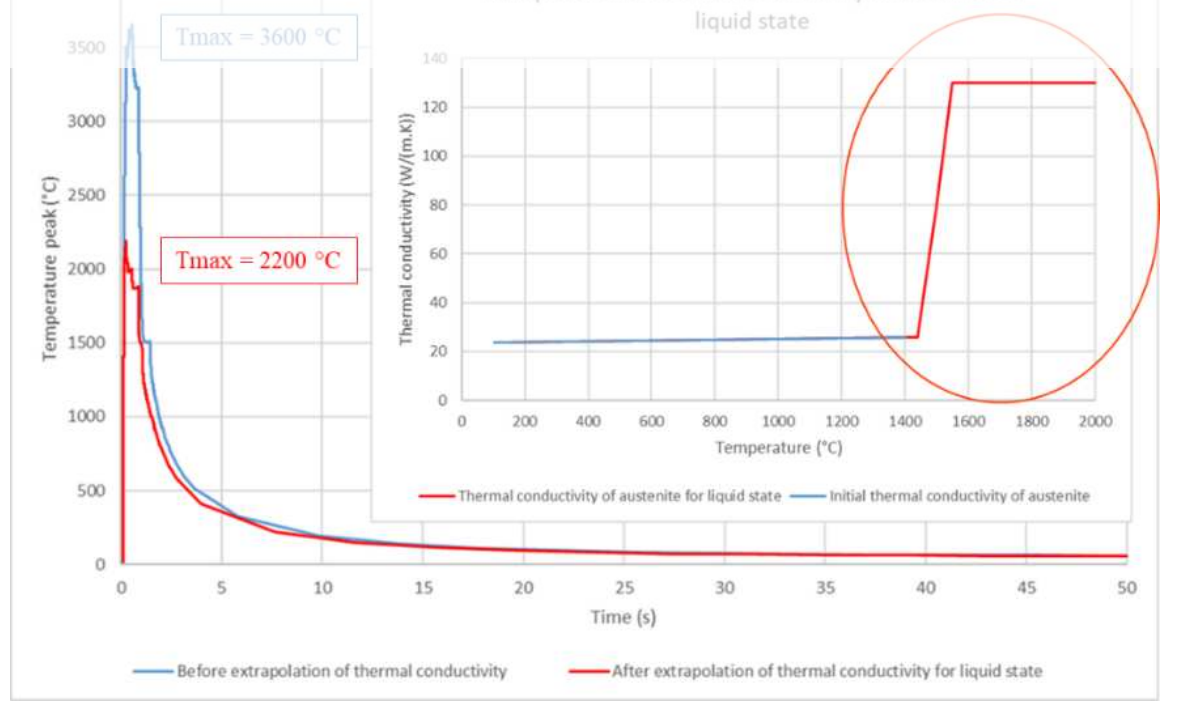

Figure 12: Extrapolation of thermal conductivity of austenite at high temperature and the impact on the maximum temperature in the liquid nugget 
Another way to see that the natural convection of the liquid steel in the nugget is taken into account, is the reduction of the nugget size (Figure 13). The left part presents the nugget (in pink) before the extrapolation of the thermal conductivity and the right part of the picture presents the nugget size after this extrapolation. One observes the reduction of the nugget size.

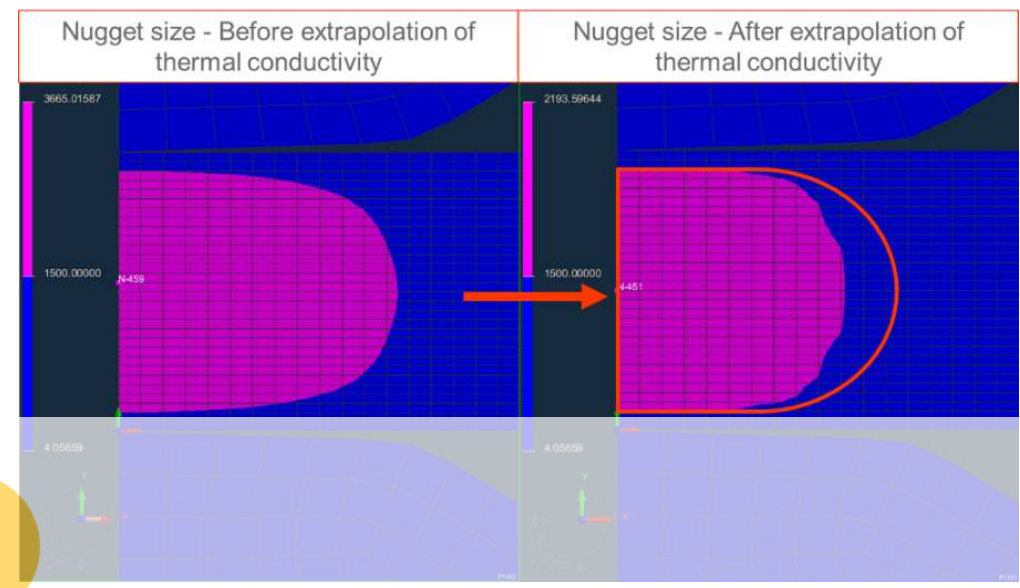

Figure 13: Numerical observation of the reduction of the liquid nugget size thanks to thermal conductivity calibration

After this last improvement of the material card, the first results of the Resistance Spot Welding simulation are stresses in the zone whe are encouraging. There properties implemented in the material card in Resistance Spot Weldin and propagating cracks when Liquid Metal Embrittlement phenomenon occurs during

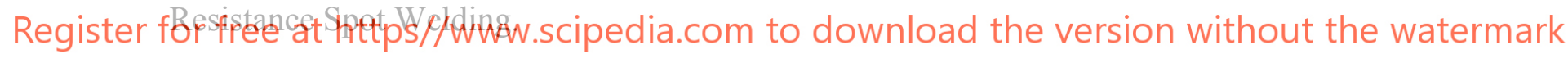

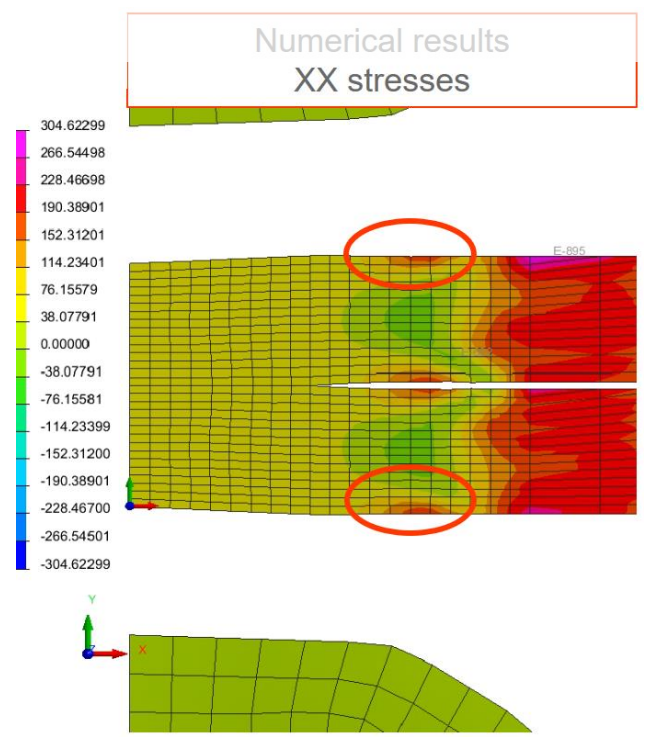

Figure 14: Preliminary results of radial stresses using a developed material card 


\section{CONCLUSIONS}

The creation of a robust and reliable numerical material card is the first important step for a reliable simulation of Resistance Spot Welding. Therefore, we set up a methodology to create and validate the material card and the multi-physical models in the Sysweld ${ }^{\circledR}$ software.

The first step is the characterization of the material properties with experimental tests, mathematical and empirical models. Then, the validation of the input data is performed through the comparison of numerical and experimental results based on dedicated tests. The final step is the validation of the Resistance Spot Welding model comparing numerical and experimental weld geometry.

The application of this methodology will end to the reliable estimation of the location and the intensity of stresses as well as temperature during the Resistant Spot Welding process.

Numerical simulation of Resistance Spot Welding process is an efficient tool to estimate stresses and temperature map during welding. This tool will be used to reduce Liquid Metal Embrittlement risk decreasing stresses during welding.

\section{ACKNOWLEDGEMENTS}

This work has been performed within the framework of FuseMetal joint laboratory (ArcelorMittal France, UTC, CNRS). This laboratory has received funding from the European Union (FEDER Région Hauts-de-France).

\section{REFERENCES}

[1] Biro, E., Chatterjee S., Cretteur L., Dilger K., Hilditch T.B., Hodgson P.D. and Hsu C. Welding and Joining of Advanced High Strength Steels (AHSS). Elsevier (2015).

[2] Kuziak, R., Kawalla, R. and Waengler, S. Advanced High Strength Steels for Automotive Industry. Archives of Civil and Mechanical Engineering (2008) 8:103-117.

[3] Cretteur, L. Assemblage dans l'automobile - Focus sur le soudage par résistance par points. ArcelorMittal Internal Presentation, 2015.

[4] Ling, Z., Wang, M., and Kong, L. Liquid Metal Embrittlement of Galvanized Steels During Industrial Processing: A Review. In Transactions on Intelligent Welding Manufacturing. Springer, Vol.3, (2017) 25-42.

[5] Jeon, W.S., Sharma, A. and Jung, J.P. Liquid Metal Embrittlement of Galvanized TRIP Steels in Resistance Spot Welding. Metals (2020) 10:787.

[6] Razmpoosh, M. H., Macwan, A., Goodwin, F., Biro, E. and Zhou, Y. Crystallographic Study of Liquid-Metal-Embrittlement Crack Path. Materials Letters (2020) 267:127511.

[7] Razmpoosh, M. H., Langelier, B., Marzbanrad, E., Zurob, H.S., Zhou, N. and Biro, E. Atomic-Scale Investigation of Liquid-Metal-Embrittlement Crack-Path: Revealing Mechanism and Role of Grain Boundary Chemistry. Acta Materialia (2021) 204: 116519.

[8] DiGiovanni, C., Biro, E. and Zhou, N.Y. Impact of Liquid Metal Embrittlement Cracks on Resistance Spot Weld Static Strength. Science and Technology of Welding and Joining (2019) 24:218-224.

[9] Ashiri, R., Haque, M.A., Ji, C.-W., Shamanian, M., Salimijazi, H.R. and Park, Y.-D. Supercritical Area and Critical Nugget Diameter for Liquid Metal Embrittlement of ZnCoated Twining Induced Plasticity Steels. Scripta Materialia (2015) 109: 6-10.

[10] Razmpoosh, M. H., Biro, E., Chen, D. L., Goodwin, F., and Zhou, Y. Liquid Metal 
Embrittlement in Laser Lap Joining of TWIP and Medium-Manganese TRIP Steel: The Role of Stress and Grain Boundaries. Materials Characterization (2018) 145: 627-633.

[11] Razmpoosh, M. H., Macwan, A., Biro, E., Chen, D.L., Peng, Y., Goodwin, F. and Zhou, Y. Liquid Metal Embrittlement in Laser Beam Welding of Zn-Coated 22MnB5 Steel. Materials \& Design (2018) 155:375-383.

[12] Béal, C. Mechanical behaviour of a new automotive high manganese TWIP steel in the presence of liquid zinc. $\mathrm{PhD}$ thesis, Institut National des Sciences Appliquées de Lyon, France, (2011).

[13] Béal, C., Kleber, X., Fabregue, D. and Bouzekri. M. Embrittlement of a Zinc Coated High Manganese TWIP Steel. Materials Science and Engineering A (2012) 543: 76-83.

[14] Béal, C., Kleber, X., Fabregue, D. and Bouzekri. M. Liquid Zinc Embrittlement of Twinning-Induced Plasticity Steel. Scripta Materialia (2012) 66:1030-1033.

[15] Tolf, E., Hedegård, J. and Melander, A. Surface Breaking Cracks in Resistance Spot Welds of Dual Phase Steels with Electrogalvanised and Hot Dip Zinc Coating. Science and Technology of Welding and Joining (2013) 18:25-31.

[16] Klinger, L. and Rabkin, E. The Effect of Stress on Grain Boundary Interdiffusion in a Semi-Infinite Bicrystal. Acta Materialia (2007) 55:4689-4698.

[17] Fanfoni, M. and Tomellini, M. The Johnson-Mehl- Avrami-Kohnogorov Model: A Brief Review. Il Nuovo Cimento D (1998) 20:1171-1182.

[18] Koistinen, D.P. and Marburger, R.E. A General Equation Prescribing the Extent of the Austenite-Martensite Transformation in Pure Iron-Carbon Alloys and Plain Carbon Steels. Acta Metallurgica (1959) 7: 59-60.

[19] Srikunwong, C. Modélisation du procédé de soudage par points. $\mathrm{PhD}$ thesis, Ecole des Mines de Paris, France (2005). 